\title{
TECHNOLOGY-ENHANCED LEARNING FOR THE DEVELOPMENT OF LEARNING MOTIVATION
}

\author{
Santa Dreimane \\ University of Latvia, Latvia
}

\begin{abstract}
Technologies are an indispensable part of the $21^{\text {st }}$ century; they shape people's lives, and it is getting more difficult to get and hold the attention of people, especially the younger generation, because of the ever-growing stream of information and information channels and platforms. In order to engage and motivate the learning of the younger generation, teachers cannot ignore the role of technologies in young people's lives.

The aim of this research is to identify opportunities to develop learning motivation and its correlation with technology-enhanced learning, as well as to compile the latest and most appropriate motivation theories in a contemporary context. To do so, a literature review was chosen as a research method to review articles obtained via the Scopus database, using the keyword 'learning motivation' to select the research units. For the systematic analysis of publications, the English language and open access availability were chosen as parameters to reduce the number of articles to review. To better understand the learning environment and the potential impact of technology-enhanced learning on learning motivation, a survey was carried out on secondary school students ( $10^{\text {th }}$ to $12^{\text {th }}$ grade) in Riga, Latvia.
\end{abstract}

Keywords: motivation theory, learning motivation, technology-enhanced learning.

\section{Introduction}

Technologies are an indispensable part of the $21^{\text {st }}$ century; they shape people's perceptions, needs and interests. It is necessary to take into account the fact that it is getting more difficult to get and hold the attention of people, especially the younger generation, because of the ever-growing stream of information and information channels and platforms that has decreased the average attention span in the past few decades.

In order to engage and motivate the learning of the younger generation, but not only the youth, teachers and researchers need to search for new approaches and methods to apply in an educational process, and they also need to remember the impact of technologies in daily life and use them in their favour. There are some new approaches like gamification, virtual 
reality, augmented reality, simulations and other technology-enhanced learning opportunities that show a positive impact on learning motivation and engagement development.

The aim of this research is to compile the latest and most appropriate motivation theories in a contemporary context and to identify the correlation between learning motivation and technology-enhanced learning in schools.

\section{Methodology}

To compile the latest and most appropriate motivation theories in a contemporary context, a literature review was chosen as a research method to review articles obtained via the Scopus database, published from 2014 to May 2019. The keyword 'learning motivation' was used to select the research units. For the systematic analysis of publications, the English language and open access availability were chosen as parameters to reduce the number of articles to review. In total, 47 articles were selected for analysis.

To better understand the learning environment and the potential impact of technology-enhanced learning on learning motivation, a survey was carried out in two secondary schools in Latvia. 84 students replied to the survey. Students were asked about themselves, their habits and their free time activities. With regard to school, they were asked for their favourite and least favourite subjects and their reasons for this. They were also asked about the methods and technologies used in lessons and about feedback from teachers.

\section{Results of the literature review}

As mentioned before, 47 articles were selected for review using a systematic analysis of publications. Of these articles, only 33 applied some of the motivation theories to the research carried out. 14 research articles, although researching learning motivation, had no theoretical background of motivation theories.

When researching learning motivation, the literature review revealed that the most commonly used motivation theories in these 33 articles were Self-Determination Theory by Edward L. Deci and Richard M. Ryan (Foster-Heinzer et al., 2016; Ho, 2017; Guo et al., 2018; Huang \& Hsu, 2019; etc.) and Self-Efficacy Theory by Albert Bandura (Chang et al., 2018; Chen, 2017; Lee, 2017; Schumacher \& Ifenthaler, 2018; Song et al., 2018; etc.), and the third most common theory was about intrinsic and extrinsic motivation (Chen et al., 2018; Hmeljak Sangawa, 2018; Kim \& Kim, 2016; Li \& Shieh, 2016; Wijaya, 2019; etc.). Although Self-Determination Theory implies intrinsic and extrinsic motivation, there were researchers who did 
not mention Ryan and Deci's theory, which is why intrinsic and extrinsic motivation is separate. The next most often used theory was Flow Theory by Mihaly Csikszentmihalyi (Ebrahimzadeh \& Alavi, 2016; Zhao et al., 2018; Chang et al., 2018; etc.). Other motivation theories detected in the articles were the four step model for promoting motivation in learning process: Attention, Relevance, Confidence, Satisfaction (ARCS) Model of motivational design by John Keller (Lin et al., 2018; Schumacher \& Ifenthaler, 2018; Setiani et al., 2019; Zhang, 2017; etc.), Goal Theory (Lin et al., 2017; Liu \& Chen, 2015; etc.) and others (see Figure 1).

Self-Determination Theory posits that there are two types of motivation intrinsic and extrinsic. The authors of this theory, Ryan and Deci, state that although intrinsic motivation is an important type of motivation, most of the activities people do are extrinsically motivated (Ryan \& Deci, 2000). Ryan and Deci identify three basic psychological needs in their theory: (1) the need for competence; (2) the need for connectedness; and (3) the need for autonomy, which nourishes self-determined motivation (Foster-Heinzer et al., 2016).

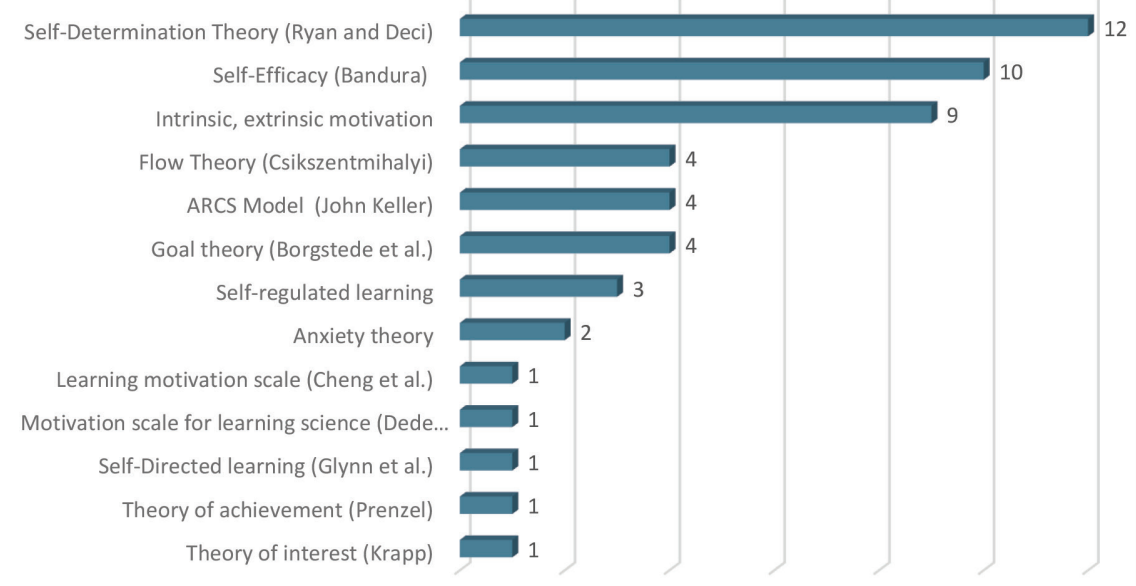

Figure 1. Motivation theories applied in research articles

In their article "Intrinsic and extrinsic motivation: classic definitions and new directions", Ryan and Deci develop a taxonomy of human motivation, explaining amotivation, four levels of extrinsic motivation and finally intrinsic motivation Associated processes with amotivation are low perceived competence, non-relevance, non-intentionality. Extrinsic motivation first level is external regulation who's associated processes are salience of extrinsic rewards and punishments. Second level of extrinsic motivation is introjection that is associated with ego involvement and 
approval from self or others. Next level is identification associated with self-endorsement of goal and conscious valuing of activity. Processes that are associated with fourth level of extrinsic motivation (integration) is hierarchical synthesis of goals and congruence. And of course mostly desired is intrinsic motivation that is based on interest, enjoyment and inherent satisfaction of a person (Ryan \& Deci, 2000, 61).

Self-Efficacy Theory by Bandura refers to our overall belief that a person can successfully achieve a particular result. Students with high self-efficacy can participate in learning activities more quickly (Chang et al., 2018). With regard to intrinsic and extrinsic motivation, the former means that the individual's motivational stimuli are coming from within, while extrinsic motivation means that the individual's motivational stimuli are coming from the outside as rewards, punishment or another outside source.

Flow Theory by Csikszentmihalyi is fully concentrated on and engaged in the immediate activity; as a result, anything else is insignificant. It is in a state of loss of self-consciousness and disregards the passage of time (as cited in Chang et al., 2018). This theory states that 'flow' is achieved when the skills and the challenge are in the right balance.

When talking about learning motivation, only 20 of the 47 articles include technology-enhanced learning, that is, $45 \%$ (see Figure 2). Of those 20 articles, e-learning was applied in seven articles, digital games in five articles, and three studies were about augmented reality. Virtual reality was also mentioned, as well as 3D, gamification and apps.

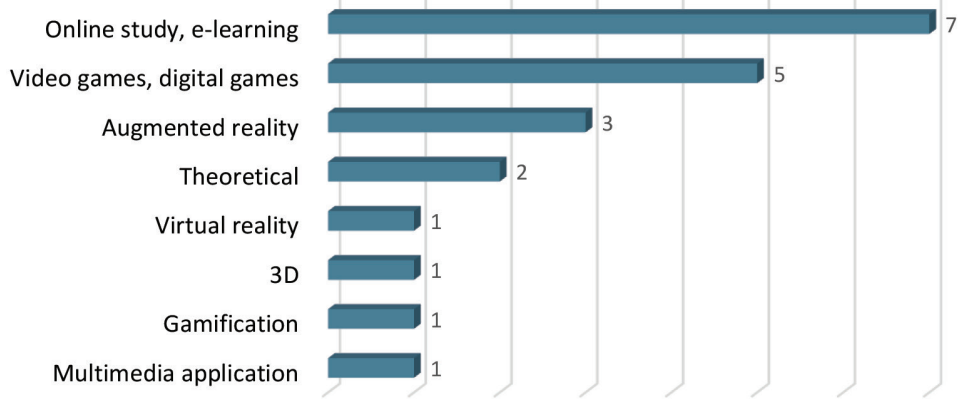

Figure 2. Technology-enhanced learning: approaches used and described in research articles

From the theories applied, Self-Determination Theory was extracted as the basic theory on which to construct a questionnaire for pupils using a taxonomy of human motivation (Ryan \& Deci, 2000). Self-Efficacy Theory and eight characteristics of Flow Theory were also used. All these theories were applied to determine pupils' level of motivation. 


\section{Results of the survey}

One of the aims of this research was to investigate the learning environment in two secondary schools in Latvia and the potential impact of technology-enhanced learning on learning motivation. To do so, an online survey was carried out in two secondary schools in Latvia - one in the capital, Riga, and the second was a rural school. Link to the online questionnaire was posted by teachers on the portal "E-class", that is accessible for teachers, pupils and their parents. Questions were divided into two section - first five questions were about pupils themselves, their habits, free time activities and technologies that they use and own. Second part of questionnaire contained 13 questions about school, pupils favourite and least favourite subjects and their reasons for this. They also replied to questions about the methods and technologies used in lessons and about feedback from teachers. During the research, the anonymity of the respondents was ensured and the requirements of research ethics were observed. 84 students replied to the online survey.

Of the 84 students who participated in the study, $72.6 \%(n=61)$ were female, and $27.4 \%(n=23)$ were male. Pupils were aged from 15 to 19 years old, and $11.9 \%(n=10)$ of them were the only child in their family.

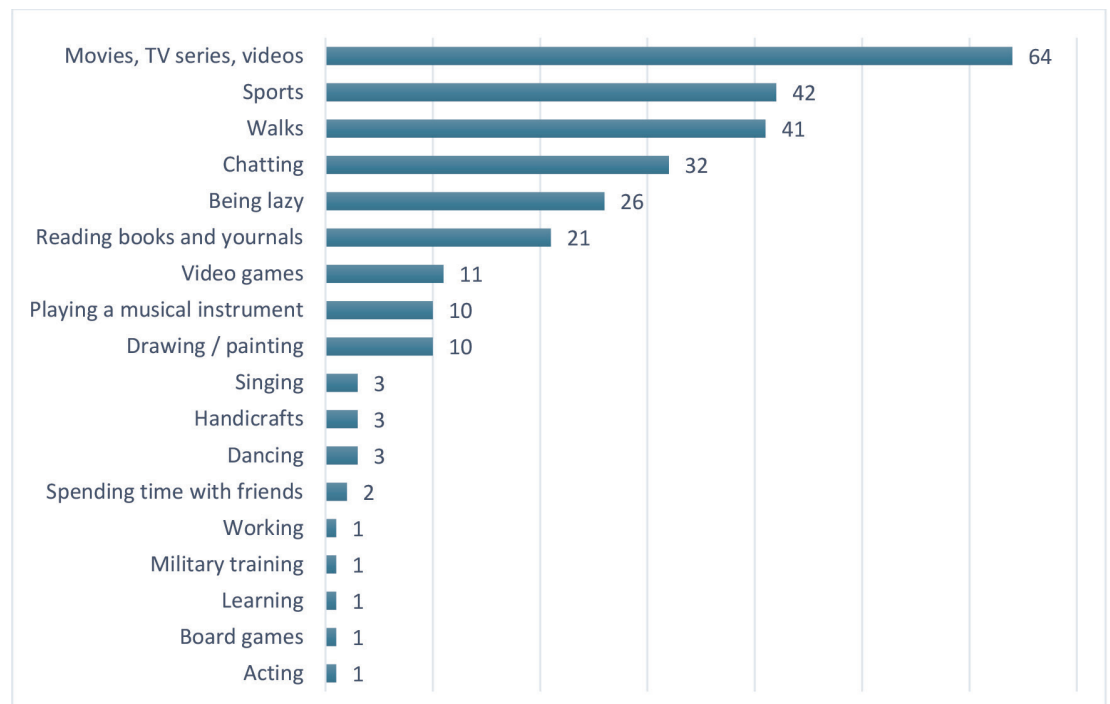

Figure 3. Free time activities of participants of the survey

The questionnaire revealed that, in their free time, these young people most of all like to watch movies, TV series or videos $(n=64)$, followed by sports activities $(n=42)$ and walks outside alone or with friends $(n=41)$. As Figure 4 shows, 32 of the respondents like to chat with friends in their 
free time, but 21 of the pupils also like to be lazy. Figure 3 displays other answers given by pupils.

Asked which of the mentioned digital devices they own or share with their family members, all 84 respondents replied that they own a smartphone for personal use and almost half of them $(n=40)$ own a laptop for personal use, while 15 own a desktop computer for personal use (see Figure 4).

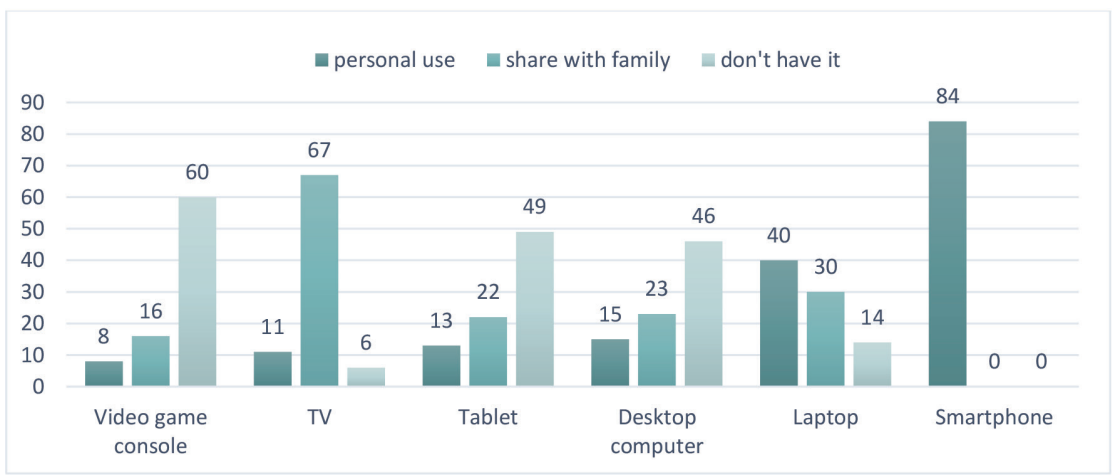

Figure 4. Technologies owned by the participants of the survey or shared with family members

\section{Favourite subject}

When pupils were asked about their favourite school subject, as Figure 5 shows, the most common answer was Maths $(n=13)$. Their next favourite subject was Psychology $(n=10)$, followed by Sports $(n=8)$ and English $(n=8)$.

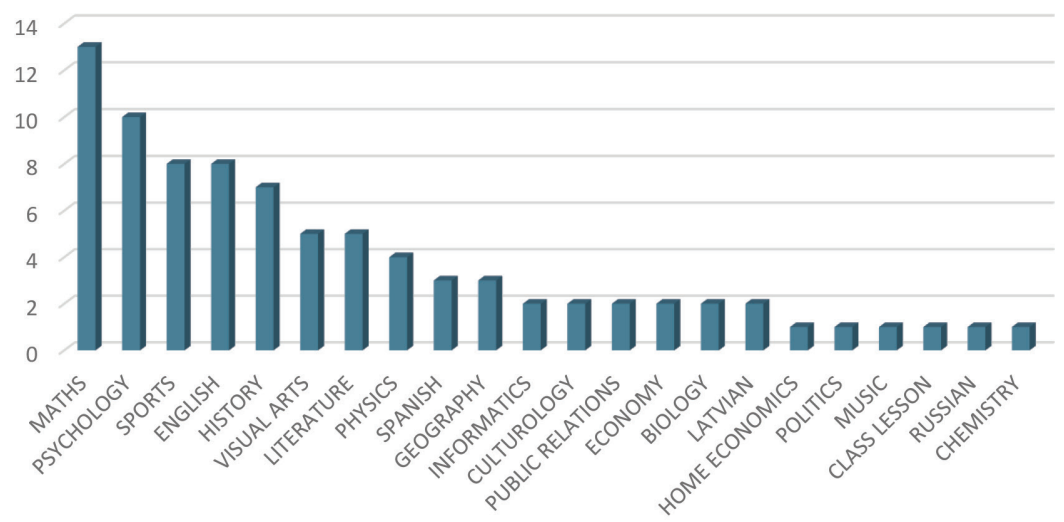

Figure 5. Favourite school subjects 
Pupils were asked for the reasons why this is their favourite subject at school. Looking closer at Maths and the given answers to the question why? $37 \%(n=7)$ of pupils' responses revealed that they find it exciting and interesting, and $37 \%(n=7)$ of responses said that they see the subject as useful in the future. Also, 26\% $(n=5)$ answered that they like the teacher.

If we analyse the reason for all the given answers about all the favourite subjects mentioned by the respondents (see Figure 6), the most common answer was "I find it exciting and interesting" ( $n=66)$, followed by the answers "I like the teacher" $(n=55)$ and "It will be useful in the future" ( $n=44)$.

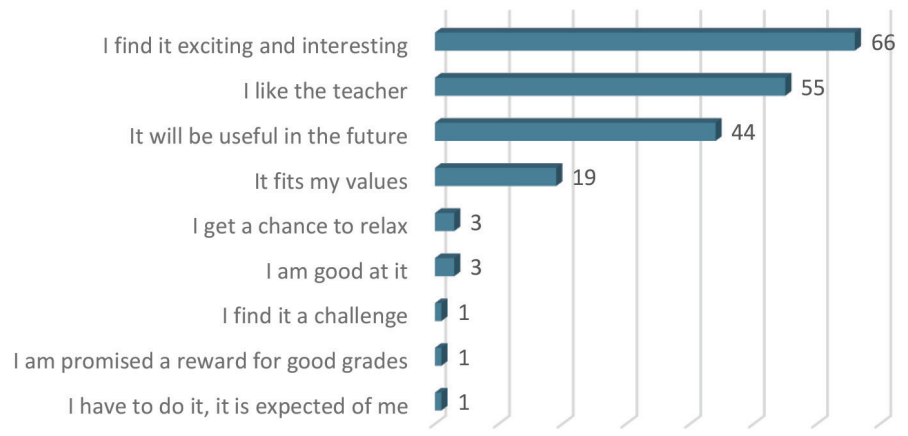

Figure 6. Answers to the question "Why is X your favourite subject?" based on the taxonomy of human motivation by Ryan and Deci

Analysing the given answers from the point of view of motivation theories, interest in the subject indicates an intrinsic motivation. Its usefulness in the future indicates an extrinsic but internalised motivation. However, liking the teacher indicates a feeling of self-belonging.

Asking the pupils to keep in mind the subject that they mentioned as their favourite, they were asked to describe the lessons, and the questions were based on the Flow Theory of Csikszentmihalyi (see Figure 7). 42 respondents answered that the lesson always has a clarity to its goals and 30 responded that goals are often clear. Feedback is given always $(n=41)$ or often $(n=25)$, and they often $(n=37)$ or always $(n=31)$ feel they have control over the tasks they are doing. And importantly, they often ( $n=50$ ) or always $(n=25)$ have complete concentration on the task. Lessons are also exciting and dynamic in most cases. 


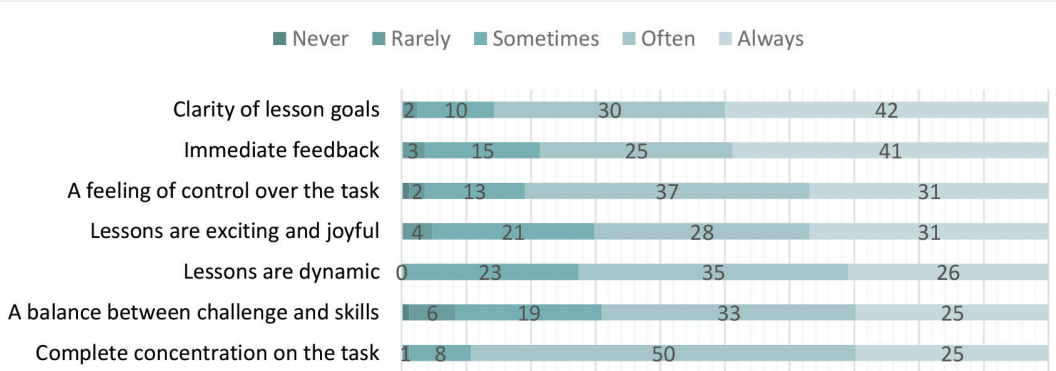

Figure 7. Description of the pupils' favourite subject based on Flow Theory

\section{Least favourite subject}

When the pupils were asked about their least favourite subject at school, the most common answer was also Maths $(n=15)$ (see Figure 8), which makes this subject controversial and dual-natured; survey data shows a correlation with the personality of the teacher. The next least favourite subjects were Chemistry $(n=13)$ and Physics $(n=12)$.

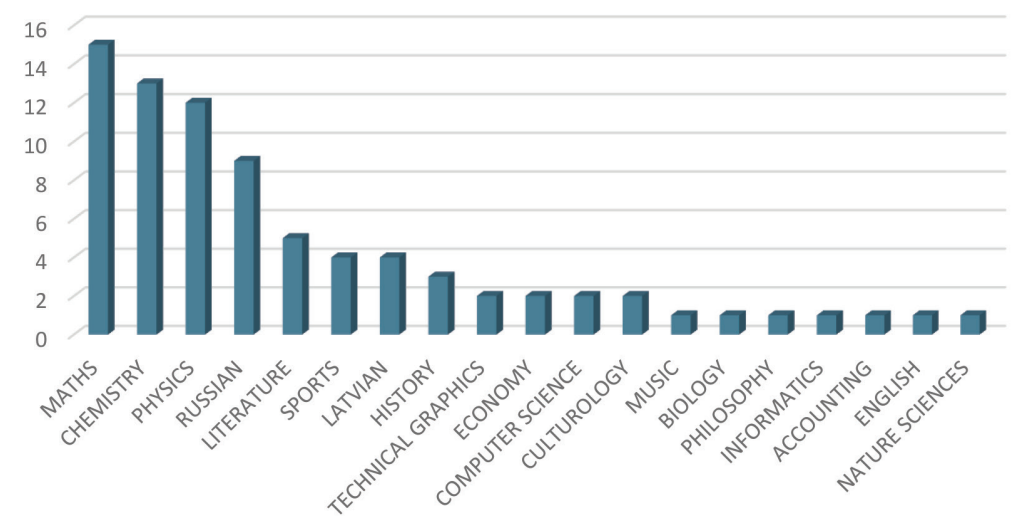

Figure 8. Least favourite school subjects

Looking closer at Maths as the least favourite subject and the reasons for this, the most common answer was "I am not good at it" $(n=6)$. Responses revealed that $22 \%(n=4)$ do not find it interesting, and $22 \%$ $(n=4)$ of respondents said that they do not like the teacher. $17 \%(n=3)$ of respondents said that the subject will not be useful in the future, while one pupil answered that his parents are putting pressure on him.

If we analyse the reasons for all the given answers about all the least favourite subjects mentioned by the respondents (see Figure 9), the most 
common answer was "I am not good at it" ( $n=56)$, followed by the answers "It doesn't interest me" $(n=45)$ and "I don't like the teacher" $(n=32)$. For 19 respondents, the subject will not be useful in the future.

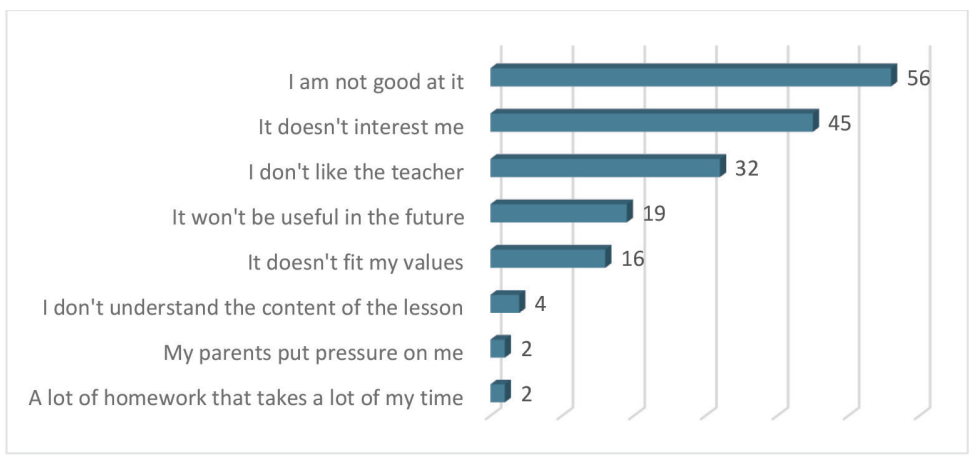

Figure 9. Answers to the question "Why is X your least favourite subject?" based on the taxonomy of human motivation by Ryan and Deci

Asking the pupils to keep in mind the subject that they mentioned as their least favourite subject, they were asked to describe these lessons, and the questions were also based on Flow Theory (see Figure 10). The respondents answered that the lessons are never $(n=33)$ or rarely $(n=33$ ) exciting or joyful and that they do not feel they have control over the tasks or a balance between the challenge and the skills that they have.

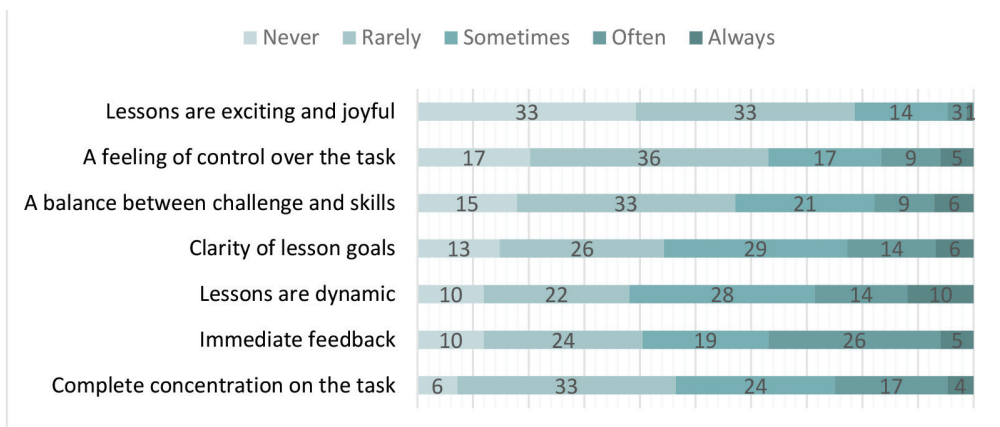

Figure 10. Description of the pupils' least favourite subject based on Flow Theory

During the online survey, pupils were also asked about the technologies used in lessons (see Figure 11). A projector is always $(n=27)$ or often ( $n=51$ ) used, and interactive board is also often $(n=49)$ or always ( $n=19$ ) used, also whiteboard. As was revealed in the study, smartphones are also sometimes $(n=40)$ or often $(n=21)$ used in lessons. 


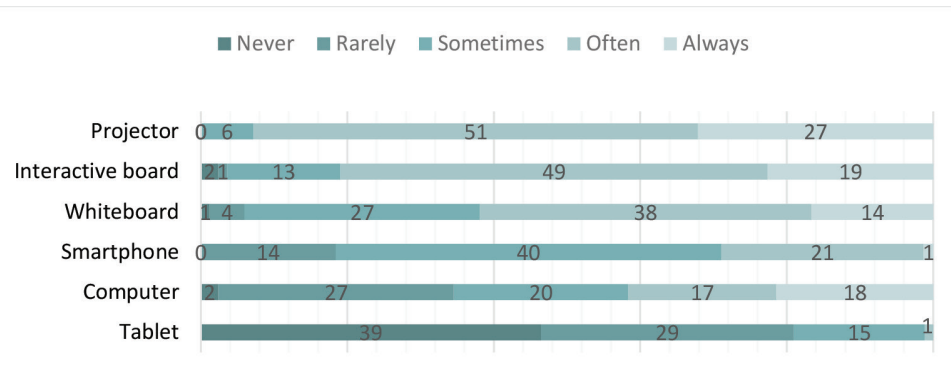

Figure 11. Frequency of use of technologies in lessons

When asked about situations when pupils need to find additional information for homework or tasks during the lessons, the most common source of information mentioned was online sources (see Figure 12), followed by friends, who are also, probably, looking for information online.

When asked what teachers allow pupils to use smartphones for, the most popular answer from respondents was to find information needed for the lesson online and sometimes to perform tasks online.

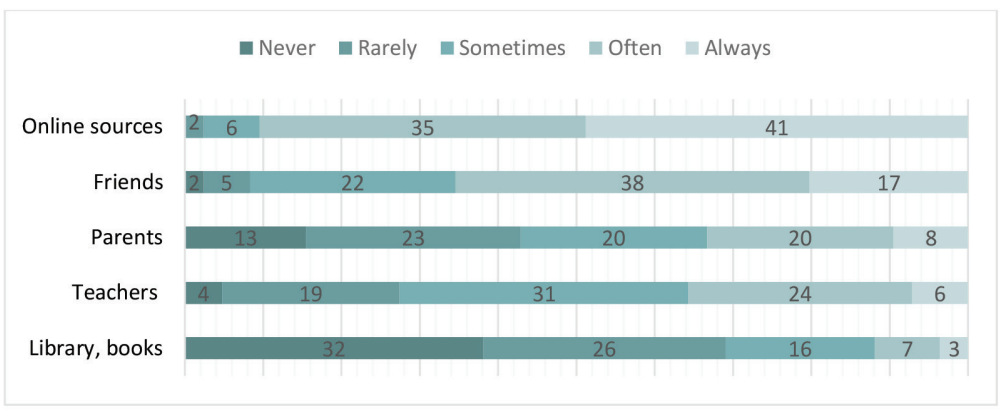

Figure 12. Additional sources of information

The analysed data revealed that students often $(n=69)$ or always ( $n=9$ ) work by themselves in lessons and that they often $(n=52)$ or always ( $n=15$ ) listen to the teacher. Group work or peer work is carried out rarely or sometimes. Games or quizzes on the topic of the lesson are never or rarely used as methods in lessons.

Feedback is very important to get a deeper understanding on a subject and mistakes that are made, which is why respondents were asked to evaluate the feedback given to them from their teachers (see Figure 13). The majority of respondents answered that they often $(n=42)$ or always $(n=13)$ get only the grade or often $(n=40)$ or always $(n=13)$ get only a pass or fail indicator. They only sometimes $(n=30)$ or rarely $(n=25)$ 
get an explanation for their mistakes or get positive comments, and rarely $(n=31)$ or sometimes $(n=29)$ get a short comment on their mistakes.

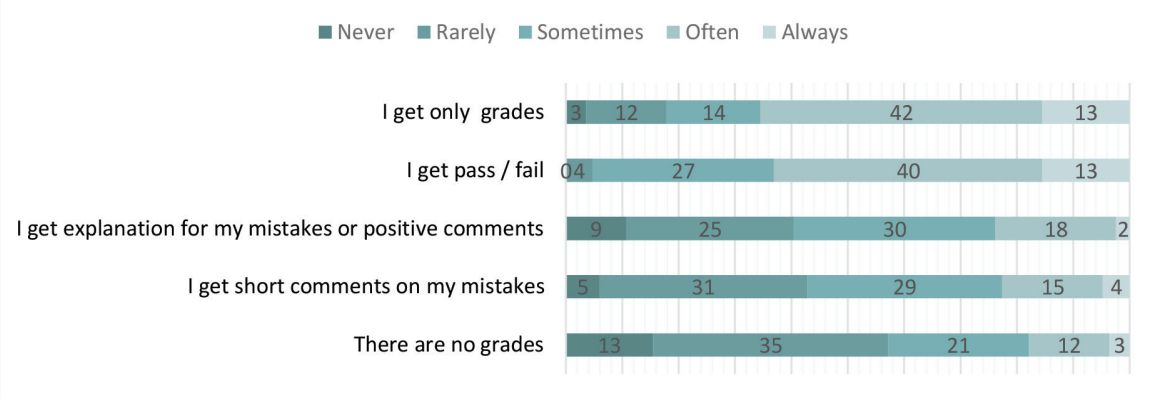

Figure 13. Feedback from teachers

As the study shows, for $68 \%$ of pupils, feedback is very important, because they want to know their mistakes so they can learn from them. $23 \%$ of respondents said that feedback is very important and they want to know why they received a particular grade. $9 \%$ of responses said that feedback from teachers would be desirable, but they can live without it. None of the respondents said that they do not need feedback from teachers.

\section{Conclusion}

Compiling motivation theories in a contemporary context with the help of a literature review revealed that the most commonly used motivation theories in research articles are Self-Determination Theory by Ryan and Deci, Self-Efficacy Theory by Bandura, Flow Theory by Csikszentmihalyi, the ARCS Model by Keller and Goal Theory.

The survey revealed that all respondents that participated in the research own a smartphone, but they do not use computers, tablets or TVs as much, because smartphones include all the options that are needed - both social and entertainment functions. Schools can use this as an opportunity to use them as an instrument in lessons. Although all surveyed students own a smartphone for personal use, it is not said that everyone has the same technical support to use them in the classroom. The teacher should assess the situation to be sure that all children are provided with this technology and act accordingly to avoid unpleasant situations.

One more important factor for learning motivation is the teacher's personality and performance in lessons. In the learning environment, the teacher is an agent who helps to develop important components of motivation, such as feedback, self-belonging, sense of worth, interest, 
challenge etc., therefore, the teacher plays an important role in the development of learning motivation.

It is hard to tell from this research whether learning motivation has some correlation with technology, because the study did not reveal what the technologies are used for in lessons. Further research with qualitative methods is needed. But it can be concluded that technology-enhanced learning gives a student external motivation that can eventually lead to intrinsic motivation if the subject is interesting for them.

According to the questionnaire carried out during this research, there are students with intrinsic motivation or motivation with an external stimulus, but there are still many students with low level of learning motivation.

Education is not taking advantage of technologies fast enough - the rate of technology use in lessons is low. Schools do not use technologies and the opportunities and innovations that they offer. Although the use of technology does not create motivated learning, its wise use can contribute to the development of external motivation. This does not mean that technologies by themselves will do any good or harm; the key is to use the opportunities technologies provide, and only their smart and thoughtful use will help to engage students and motivate learning at a deeper level.

\section{References}

Chang, C. C., Kuo, C. G., \& Chang, Y. H. (2018). An assessment tool predicts learning effectiveness for project-based learning in enhancing education of sustainability. Sustainability (Switzerland), 10(10). doi:10.3390/su10103595.

Chen, Q., Kong, Y., Gao, W., \& Mo, L. (2018). Effects of socioeconomic status, parent-child relationship, and learning motivation on reading ability. Frontiers in Psychology, 9(JUL). doi:10.3389/fpsyg.2018.01297.

Chen, Y. C. (2017). Empirical study on the effect of digital game-based instruction on students' learning motivation and achievement. Eurasia Journal of Mathematics, Science and Technology Education, 13(7), 3177-3187. doi:10.12973/eurasia.2017.00711a.

Ebrahimzadeh, M., \& Alavi, S. (2016). Motivating EFL students: E-learning enjoyment as a predictor of vocabulary learning through digital video games. Cogent Education, 3(1). doi:10.1080/2331186X.2016.1255400.

Forster-Heinzer, S., Holtsch, D., Rohr-Mentele, S., \& Eberle, F. (2016). Do they intend to stay? An empirical study of commercial apprentices' motivation, satisfaction and intention to remain within the learned occupation. Empirical Research in Vocational Education and Training, 8(1). doi:10.1186/s40461-016-0041-0.

Guo, H., Tong, F., Wang, Z., Min, Y., \& Tang, S. (2018). English- vs. Chinese-medium instruction in Chinese higher education: A quasi-experimental comparison. Sustainability (Switzerland), 10(11). doi:10.3390/su10114230.

Hmeljak Sangawa, K. (2018). Japanese language teaching at tertiary level in Slovenia: Past experiences, future perspectives. Acta Linguistica Asiatica, 8(1), 51-64. doi:10.4312/ ala.8.1.51-64. 
Ho, S. S. H. (2017). The impact of Taiwanese college students' learning motivation from self-determination perspective on learning outcomes: Moderating roles of multi-traits. Kuram Ve Uygulamada Egitim Bilimleri, 17(3), 1015-1034. doi:10.12738/ estp.2017.3.0406.

Huang, W. Y., \& Hsu, C. C. (2019). Research on the motivation and attitude of college students' physical education in Taiwan. Journal of Physical Education and Sport, 19, 69-79. doi:10.7752/jpes.2019.s1011.

Kim, T. Y., \& Kim, Y. K. (2016). A quasi-longitudinal study on English learning motivation and attitudes: The case of South Korean students. Journal of Asia TEFL, 13(2), 138-155. doi:10.18823/asiatefl.2016.13.2.5.138.

Lee, E. (2017). Effects of South Korean high school students' motivation to learn science and technology on their concern related to engineering. Kuram Ve Uygulamada Egitim Bilimleri, 17(2), 549-571. doi:10.12738/estp.2017.2.0160.

Li, J. Y., \& Shieh, C. J. (2016). A study on the effects of multiple goal orientation on learning motivation and learning behaviors. Eurasia Journal of Mathematics, Science and Technology Education, 12(1), 161-172. doi:10.12973/eurasia.2016.1221a.

Lin, M. H., Chen, H. C., \& Liu, K. S. (2017). A study of the effects of digital learning on learning motivation and learning outcome. Eurasia Journal of Mathematics, Science and Technology Education, 13(7), 3553-3564. doi:10.12973/eurasia.2017.00744a.

Lin, P. H., Huang, Y. M., \& Chen, C. C. (2018). Exploring imaginative capability and learning motivation difference through picture E-book. IEEE Access, 6, 63416-63425. doi:10.1109/ACCESS.2018.2875675.

Liu, H. J., \& Chen, C. W. (2015). A comparative study of foreign language anxiety and motivation of academic- and vocational-track high school students. English Language Teaching, 8(3), 193-204. doi:10.5539/elt.v8n3p193.

Ryan, R. M., \& Deci, E. L. (2000). Intrinsic and extrinsic motivation: classic definitions and new directions. Contemporary Education Psychology, 25(1): 54-67. doi:10.1006/ ceps.1999.1020.

Schumacher, C., \& Ifenthaler, D. (2018). The importance of students' motivational dispositions for designing learning analytics. Journal of Computing in Higher Education, 30(3), 599-619. doi:10.1007/s12528-018-9188-y.

Setiani, R., Sanjaya, I. G. M., \& Jatmiko, B. (2019). ARICESA as an alternative learning model to improve learning motivation and understanding of student concepts. International Journal of Instruction, 12(2), 383-398. doi:10.29333/iji.2019.12225a.

Song, Y., Chang, W., \& Chang, J. (2018). The effective factors of professional learning: Study on accounting firms in Korea. Journal of Asian Finance, Economics and Business, 5(2), 81-94. doi:10.13106/jafeb.2018.vol5.no2.81.

Wijaya, N. H. S. (2019). Linking job dissatisfaction, learning motivation, creative work involvement, and proactive personality. Problems and Perspectives in Management, 17(1), 32-41. doi:10.21511/ppm.17(1).2019.04.

Zhang, W. (2017). Design a civil engineering micro-lecture platform based on the ARCS model perspective. International Journal of Emerging Technologies in Learning, 12(1), 107-118. doi:10.3991/ijet.v12i01.6487.

Zhao, Y., Niu, G., Hou, H., Zeng, G., Xu, L., Peng, K., \& Yu, F. (2018). From growth mindset to grit in Chinese schools: The mediating roles of learning motivations. Frontiers in Psychology, 9(OCT). doi:10.3389/fpsyg.2018.02007. 